\title{
Acute Liver Failure
}

Troy Fonda, Iswan Abbas Nusi, Poernomo Boedi Setiawan, Herry Purbayu, Titong Sugihartono, Ummi Maimunah, Ulfa Kholili, Budi Widodo, Husin Thamrin, Amie Vidyani and Muhammad Miftahussurur

${ }^{1}$ Department of Internal Medicine, Faculty of Medicine, University of Airlangga, Dr. Soetomo General Hospital, Jl. Prof dr. Moestopo 47 Surabaya 60132 Indonesia

apji@fk.unair.ac.id

Keywords: $\quad$ Acute Liver Failure, Hepatic Encephalopathy, Jaundice, Coagulopathy.

Abstract: $\quad$ Acute liver failure is a sudden decline in liver function with jaundice, coagulopathy (INR $\geq 1.5$ ) and hepatic encephalopathy in patients with no history of liver disease and it emerges in less than 26 weeks. The interval between the occurrence of yellow symptoms and hepatic encephalopathy of less than 7 days is hyperacute, $8-28$ days is called acute, and more than 28 days but less than 26 weeks is called subacute. If the interval is more than 6 months, it is called chronic liver failure. The etiology of most cases is due to the use of acetaminophen. The treatment of ALF should be performed in the ICU to minimize the risk of infection, cerebral edema, bleeding, respiratory failure, and other organ function disorders. The prognosis of ALF depends on the degree of encephalopathy, prolongation of prothrombin time, serum bilirubin level, and kidney function.

\section{INTRODUCTION}

Acute liver failure (ALF) is one of the manifestations of hepatocellular failure, where liver function declines suddenly without a prior liver disease. Symptoms include jaundice, coagulopathy, and damage to many organs (Khashab, Tector, \& Kwo, 2007). The number of ALF cases is about 10 to 1 million people each year (Bernal \& Wendon, 2013) 2,000-2,800 cases of which are found in the United States and about $15 \%$ cases are undetectable (Shahani, 2016).

ALF can be caused by many things. The most common cause in the United States and Europe is the use of acetaminophen, while viral hepatitis is the cause in Japan and Asia (Khashab et al., 2007; Sugawara, Nakayama, \& Mochida, 2012). Finding the cause of ALF and addressing the causes will provide a better prognosis even though the ALF mortality rate in the world is still relatively high (Blackmore \& Bernal, 2015).

Management of ALF is quite complex and depends on the cause. If the healing process cannot take place then liver transplantation is the treatment option used in Europe and the United States, whereas Japan has the therapy choice of plasma exchange and hemodiafiltration (Sugawara et al., 2012).

Based on the data, it is important for a specialist in internal medicine to know more about ALF and its treatment. Early detection of ALF, its causes and proper treatment are expected to reduce ALF mortality. This report discusses ALF including definition, classification, pathophysiology, etiology, diagnosis, management, and prognosis. This paper is expected to help specialists in internal medicine to better understand and manage ALF.

\section{DEFINITION}

ALF, commonly referred to as fulminant liver failure is a hepatic encephalopathy syndrome and bleeding that occurs due to malfunction of liver cells caused by liver cell death within the first 26 weeks without previous liver disease (Bernal \& Wendon, 2013; Schilsky, Honiden, Arnott, \& Emre, 2009; Sugawara et al., 2012). ALF is a sudden decline in liver function with coagulopathy (INR $\geq 1.5$ ) and hepatic encephalopathy in patients with no previous liver disease and it emerges in less than 26 weeks (Setiawan, 2015). 


\section{CLASSIFICATION}

ALF classification is divided into three based on the interval between the occurrence of yellow symptoms and hepatic encephalopathy, i.e., less than 7 days is hyperacute, 8-28 days is called acute, and more than 28 days but less than 26 weeks is called subacute (Setiawan, 2015). More details are given in Table 1.

Table 1: ALF Classification.

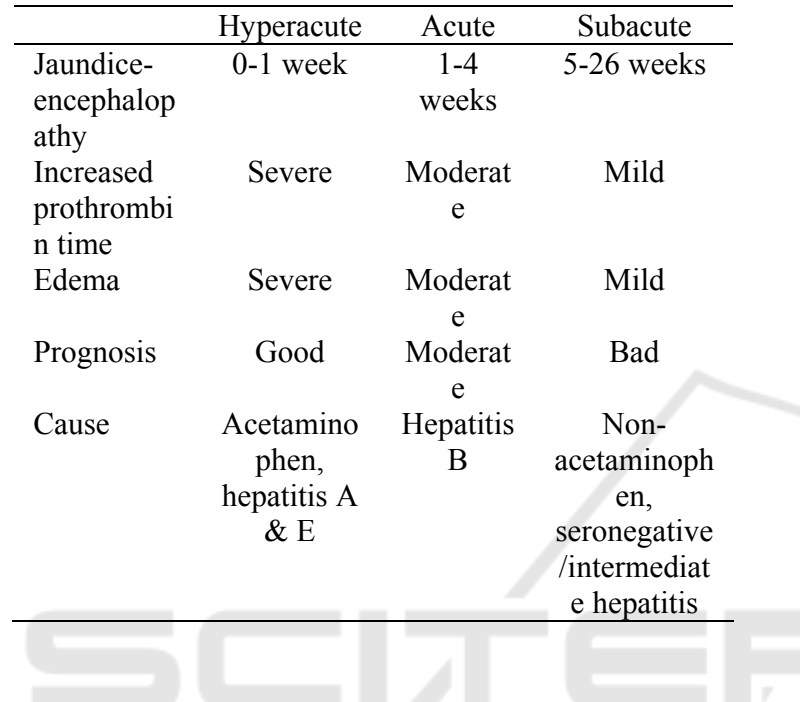

\section{PATHOPHYSIOLOGY}

Damage to liver cells is caused by direct damage and response by the immune system through activation of monocytes, macrophages, dendritic cells, leukocytes, NK cells and HCV (natural killer T) cells. Injury to hepatocytes will cause damage and liver cell death through necrosis and apoptosis. Apoptosis occurs when ATP is available. If ATP is not sufficient, necrosis will happen (Schilsky et al., 2009). Cells with necrosis will suffer damage to the integrity of the cell membrane; thus, it ruptures and releases cytosolic proteins such as lactate dehydrogenase (LDH), alanine aminotransferase (ALT), aspartate aminotransferase (AST), and ferritin (Schilsky et al., 2009).

The discharge of cell and ROS contents will activate stellate cells in the liver which attract and activate tissue macrophages through $\mathrm{CC}$-chemokine ligand 2 (CCL2)-CC-chemokine receptor 2 (CCR2). Then, it engulfs necrotic cells which undergo apoptosis. Stellate and macrophage cells also release proinflammatory cytokines such as IL-6, TNF, IL$1 \beta$, and TGF $\beta$, attracting T cells and neutrophils. TGF $\beta$ causes stellate cell differentiation into myofibroblasts. Platelet-derived growth factor
(PDGF) causes proliferation of myofibroblasts. Myofibroblasts produce $\alpha$-smooth muscle actin ( $\alpha$ SMA) and collagen I. Macrophages have a latent capacity to decrease the scar matrix through metalloproteinase (MMP) matrix secretion; however, protease activity is inhibited by the production of tissue inhibitor of metalloproteinase by myofibroblasts and macrophages which results in progressive matrix deposition and the accumulation of scars. Improved intestine permeability and liver lipopolysaccharide (LPS)-Toll-like receptor 4 (TLR4) signaling cause fibrogenesis of liver stellate cells with active TLR4. It produces chemokines and express adhesion molecules that recruit macrophages to the site of injury. Chronic inflammation and interactions between cell matrixes lead to fibrogenesis (Pellicoro, et al., 2014).

\section{ETIOLOGY}

\subsection{Virus}

Hepatitis $\mathrm{A}$ and $\mathrm{E}$ viruses are the most common cause of acute liver failure with a mortality up to $50 \%$ in developing countries, whereas hepatitis B is the leading cause in Asian and Mediterranean countries (Bernal \& Wendon, 2013). In addition to the hepatitis virus, herpes simplex, herpes zoster, varicella zoster, CMV, Epstein Barr virus, and parvovirus can also cause acute liver failure (Shahani, 2016; Thayapararajah, Gulka, Al-Amri, Das, \& Young, 2013).

\subsection{Use of drugs}

Use of drugs that cause acute liver damage occurs in $50 \%$ of cases in the United States (Bernal \& Wendon, 2013; Ichai \& Samuel, 2008). Acetaminophen causes more damage to the central liver zone and port system (Chen et al., 2015).

\subsection{Other causes}

Other causes of ALF include patients with heart problems, respiratory failure, sepsis, circulatory disorders, hypoxia hepatitis or acute ischemia hepatocellular injury (Bernal \& Wendon, 2013), and misuse of MDMA (3,4-methylenedioxy-Nmethylamphetamine, or cocaine) at a young age (Ichai \& Samuel, 2008). Budd Chiari syndrome will cause obstruction in the blood liver flow resulting in 
acute liver failure (Schilsky et al., 2009). Fungus amanita causes vomiting, diarrhea, impaired liver function, and other organs. Wilson disease is a condition when a buildup of copper causes liver damage, usually accompanied by hemolytic nonimmune anemia (Jin, Chen, Jiang, \& Lu, 2012).

\section{DIAGNOSIS}

It is necessary to ask about the history of drug usage especially acetaminophen, hepatotoxic substances, fever, signs of hepatitis, and history of previous disease during anamnesis. It is necessary to evaluate the patient's mental status, hepatic and lien tackling, presence or absence of ascites, jaundice, as well as signs of chronic liver failure, e.g. spider nevi, gynecomastia, and palmar erythema on physical examination (Jin et al., 2012). Examination of the mental status performed includes awareness, size and comparison of the left-right pupil, pupil reflex quality, and the presence or absence of clonus. Evaluation of encephalopathy uses West Haven Criteria (Schachinger et al., 2009).

Blood tests required are complete blood, hemostasis physiology, liver function, kidney function, sugar levels and electrolytes. Analysis of blood gas and virological (hepatitis, or other viruses), autoimmune markers, microbiology (blood cultures, urine, sputum), pregnancy tests, and toxicology also need to be examined. Radiological examination is performed to determine the size and circumstances of liver, lien, artery and hepatic vein, the presence of tumors, the state of other abdominal organs with an abdominal ultrasound, head CT scan, and thorax photographs. It is called acute liver failure if the following symptoms occur within 8-26 weeks of the symptoms of hepatitis occurring (Setiawan, 2015; Sugawara et al., 2012).

\section{MANAGEMENT}

\subsection{Metabolism}

Patients with acute liver failure experience hypoglycemia due to reduced glycogen storage, failure of gluconeogenesis, and increased insulin secretion; thus, intravenous glucose is administered. Intravenous fluids also need to be taken into account, and prevention of hyponatremia should be done because it can cause cerebral edema. These conditions are very influential on the nutrition of patients; thus, there is a need to pay attention to the patient's diet. The dietary administration is in accordance with the International Society for Hepatic Encephalopathy and Nitrogen Metabolism that includes the number of calories, protein, and mode of administration. Calories given are 5-30 $\mathrm{kcal} / \mathrm{kg} \mathrm{BW/day} \mathrm{(Schilsky} \mathrm{et} \mathrm{al.,} \mathrm{2009).} \mathrm{Dietary}$ protein given is $1-1.5 \mathrm{~g} / \mathrm{kg} \mathrm{BW} /$ day with monitoring of blood ammonia levels, and proteins are needed for immune system formation and increased catabolism (Bernal \& Wendon, 2013). An example of an EH diet in Dr. Soetomo General Hospital Surabaya can be seen in Table 2.

\subsection{Infection}

The greatest cause of death is an infection because the liver cells are damaged and bacterial translocation occurs. The most common infections invade the lungs, urinary tract, and blood. The most common causes are Staphylococcus, Streptococcus, and enteric gram-bacilli, and fungal infections, particularly candida. Antibiotics given are empirical antibiotics, broad spectrum for positive and negative gram, the third generation of cephalosporins, and while awaiting the results of culture, vancomycin (Schilsky et al., 2009; Shahani, 2016). If the condition does not improve, then antifungal administration should be considered. The choice of antifungal is fluconazole with a dose of $10 \mathrm{mg}$ /day or amphotericin B $20 \mathrm{mg} /$ day. Administration of an amphotericin nebulizer $(30 \mathrm{mg}$ in $5 \mathrm{ml}$ of $0.9 \%$ saline) may be given if there are respiratory infections due to fungi (Kayaalp, Ersan, \& Yilmaz, 2014).

Table 2: Example of EH diet in Dr. Soetomo General Hospital Surabaya Indonesia.

\begin{tabular}{cccllc}
\hline Type & \multicolumn{1}{c}{ Calories } & \multicolumn{1}{c}{ Proteins } & \multicolumn{1}{c}{$\begin{array}{c}\text { Administration } \\
\text { Mode }\end{array}$} & \multicolumn{1}{c}{ Indication } & $\begin{array}{c}\text { Parentera } \\
1\end{array}$ \\
\hline Diet EH 1 & $1,700 \mathrm{kcal}$ & $7 \%(30 \mathrm{~g})$ & orally & hepatic precoma is resolved & AARC \\
Diet EH 2 & $1,400 \mathrm{kcal}$ & $5 \%(18 \mathrm{~g})$ & orally & hepatic precoma (I) & AARC \\
Diet EH 3 & $1,200 \mathrm{kcal}$ & $1 \%(4 \mathrm{~g})$ & enteral & hepatic coma (II, III, IV) & AARC \\
\hline
\end{tabular}




\subsection{Heart Failure and Respiratory Disorders}

Lack of intake, vomiting, and vasodilation can cause hypotension. The porta pressure will increase, blood collection occurs in the splanchnic so that venous return decreases, arterial dilatation occurs due to disrupted blood vessel muscle and sepsis, and this accumulation will cause hypotension. The therapy is aimed at improving tissue perfusion and oxygen adequacy. The liquid selected for resuscitation is normal. Dopamine and norepinephrine can increase blood flow to the liver and cardiac output; however, they have a tachycardia effect. Dopamine is a better option in this case (Setiawan, 2015). Dobutamine is used in the event of a left ventricular disorder, but it can lead to worse hypotension due to arterial dilatation. If there is no intracranial pressure gauge, then the target of therapy is MAP $>80 \mathrm{mmHg}$. If arrhythmia occurs, vasopressin is given as many as $0.04 \mathrm{U} /$ minute and norepinephrine is gradually reduced. Cardiovascular cardiac instability may lead to relative adrenal insufficiency, hydrocortisone therapy given is $200-300 \mathrm{mg} / \mathrm{day}$ and the dose is divided (Bernal \& Wendon, 2013).

\subsection{Neurological disorders}

The decrease in the amount of ammonia absorption by the brain and decrease in the increase of intracranial pressure are achieved by administration of osmotherapy (intravenous hypertonic saline fluid with $20 \mathrm{ml}$ of $30 \% \mathrm{NaCl}$ or $200 \mathrm{ml}$ of $3 \% \mathrm{NaCl}$, the sodium serum is maintained at $145-155 \mathrm{mmol}$ per liter, $2 \mathrm{ml}$ of $20 \%$ mannitol per $\mathrm{kg}$ body weight or $0.5-1 \mathrm{~g}$ per $\mathrm{kg}$ body weight, serum osmolarity of $<$ 320 mOsm per liter) (Bernal \& Wendon, 2013; Jin et al., 2012; Setiawan, 2015).

The head being held up $30^{\circ}$ can facilitate cerebrospinal flow and reduce intracranial pressure. The action to move the neck should be avoided to prevent the occurrence of jugular venous compression. Hypothermia $\left(32-34^{\circ} \mathrm{C}\right)$ can decrease metabolism and seizure events, normalize perfusion to the brain, decrease ammonia to the brain, and stabilize hemodynamics; meanwhile, the side-effects are arrhythmias, bleeding, electrolyte imbalance, hyperglycemia, and metabolic disorders. Rewarming is carried out with an increase in the temperature at $1^{\circ} \mathrm{C} /$ hour to $1{ }^{\circ} \mathrm{C} /$ day (Jin et al., 2012; Schilsky et al., 2009).

Administration of indomethacin $(0.5 \mathrm{mg} / \mathrm{kg}$ body weight) may help to overcome encephalopathy (Bernal \& Wendon, 2013). Hyperventilation can be performed to reduce intracranial pressure. Patients with hepatic encephalopathy of grade 3 or more should be intubated with appropriate sedation and analgesics (Propofol and fentanyl). Propofol is preferred because of its shorter duration of action, and it may decrease cerebrospinal fluid production and decrease intracranial pressure. Preferably pain therapy is fentanyl over morphine or meperidine, because the active metabolism of morphine and meperidine may decrease the seizure threshold (Schilsky et al., 2009).

\subsection{Impaired kidney function}

Kidney failure can occur in $50 \%$ of cases of acute liver failure, especially in elderly patients. This can be due to several causes of GHA being nephrotoxic such as acetaminophen, sulfonamide, halothane, toxic fungal poisons, and hypoxic hepatitis. It causes acute tubular necrosis and hepatorenal syndrome. It is called acute tubular necrosis if sodium in urine was > $20 \mathrm{mmol} / \mathrm{L}$ (Bernal \& Wendon, 2013; Schilsky et al., 2009). Hemodialysis may be an option if progressive acute renal failure occurs (Schilsky et al., 2009; Setiawan, 2015).

\subsection{Bleeding}

Prolongation of prothrombin time occurs due to synthesis disorders and increased procoagulation factor requirements. Meanwhile, the cause of thrombocytopenia is still not recognized clearly. Vitamin $\mathrm{K}$ is administered at a dose of $10 \mathrm{mg}$ intravenously or subcutaneously. Platelet transfusion is performed if the platelets are $<10,000$ or an invasive action is performed $(50,000-70,000)$ (Schilsky et al., 2009; Setiawan, 2015). The exchange of plasmapheresis, as well as the provision of recombinant factor VIIa, may be the treatment option (Stravitz \& Kramer, 2009). If FFP transfusion fails to correct the prothrombin time and platelet amount $(>50,000)$ then a recombinant factor of 7 $(40 \mathrm{mg} / \mathrm{kg})$ is preferred. Patients with hypofibrinogenemia $(<100 \mathrm{mg} / \mathrm{dl})$ can be given cryoprecipitate (Schilsky et al., 2009).

One option of ALF therapy is liver transplantation. Life success rate in the first year is about $79 \%$ and $72 \%$ in the first 5 years. Death is usually caused by an infection in the first 3 months, neurological disorders, and the rejection of donor organs (Bernal \& Wendon, 2013; Schilsky et al., 2009). The risk of death will increase in elderly patients and those who receive organs from donors 
with different blood types (Bernal \& Wendon, 2013; Setiawan, 2015).

\section{PROGNOSIS}

Factors influencing the success of therapy in ALF patients include the degree of encephalopathy, patient age, and cause of ALF. The success in encephalopathy degree I-II is about $65-70 \%$; however, degree IV has success of less than $20 \%$. The survival rate is $50 \%$ without a liver transplant in ALF patients due to acetaminophen, hepatitis A, ischemia hepatitis, and pregnancy; meanwhile, the other survival rate is below $25 \%$ (Gotthardt et al., 2007).

\section{SUMMARY}

ALF is a sudden decline in liver function with jaundice, coagulopathy (INR $\geq 1.5$ ), and hepatic encephalopathy in patients without previous liver disease and it emerges in less than 26 weeks. The interval between the occurrence of yellow symptoms and hepatic encephalopathy of less than 7 days is hyperacute, 8-28 days is called acute, and more than 28 days but less than 26 weeks is called subacute. If the interval is more than 6 months, it is called chronic liver failure. The etiology of most causes is due to the use of acetaminophen. The treatment of ALF should be conducted in the ICU to minimize the risk of infection, cerebral edema, bleeding, respiratory failure and other organ function disorders. The prognosis of ALF depends on the degree of encephalopathy, prolongation of prothrombin time, serum bilirubin level, and kidney function.

\section{REFERENCES}

EE

Bernal, W., \& Wendon, J. (2013). Acute liver failure. $N$ Engl J Med, 369(26), 2525-2534. doi: 10.1056/NEJMra1208937

Blackmore, L., \& Bernal, W. (2015). Acute liver failure. Clin Med (Lond), 15(5), 468-472. doi: 10.7861/clinmedicine.15-5-468

Chen, L. Y., Yang, B., Zhou, L., Ren, F., Duan, Z. P., \& Ma, Y. J. (2015). Promotion of mitochondrial energy metabolism during hepatocyte apoptosis in a rat model of acute liver failure. Mol Med Rep, 12(4), 5035-5041. doi: 10.3892/mmr.2015.4029

Gotthardt, D., Riediger, C., Weiss, K. H., Encke, J., Schemmer, P., Schmidt, J., \& Sauer, P. (2007). Fulminant hepatic failure: etiology and indications for liver transplantation. Nephrol Dial Transplant, 22 Suppl 8, viii5-viii8. doi: 10.1093/ndt/gfm650

Ichai, P., \& Samuel, D. (2008). Etiology and prognosis of fulminant hepatitis in adults. Liver Transpl, 14 Suppl 2, S67-79. doi: 10.1002/lt.21612

Jin, Q., Chen, E., Jiang, J., \& Lu, Y. (2012). Acute hepatic failure as a leading manifestation in exertional heat stroke. Case Rep Crit Care, 2012, 295867. doi: $10.1155 / 2012 / 295867$

Kayaalp, C., Ersan, V., \& Yilmaz, S. (2014). Acute liver failure in Turkey: a systematic review. Turk $J$ Gastroenterol, 25(1), 35-40. doi: 10.5152/tjg.2014.4231

Khashab, M., Tector, A. J., \& Kwo, P. Y. (2007). Epidemiology of acute liver failure. Curr Gastroenterol Rep, 9(1), 66-73.

Schachinger, V., Assmus, B., Erbs, S., Elsasser, A., Haberbosch, W., Hambrecht, R., . . . investigators, R.A. (2009). Intracoronary infusion of bone marrowderived mononuclear cells abrogates adverse left ventricular remodelling post-acute myocardial infarction: insights from the reinfusion of enriched progenitor cells and infarct remodelling in acute myocardial infarction (REPAIR-AMI) trial. Eur $J$ Heart Fail, 11(10), 973-979. doi: 10.1093/eurjhf/hfp113

Schilsky, M. L., Honiden, S., Arnott, L., \& Emre, S. (2009). ICU management of acute liver failure. Clin Chest Med, 30(1), 71-87, viii. doi: 10.1016/j.ccm.2008.10.001

Setiawan, P. B. (2015). Kegagalan hepatoselular: EIMED PAPDI Kegawatdaruratan Penyakit Dalam.

Shahani, L. (2016). Fulminant hepatic failure secondary to acyclovir-resistant herpes simplex virus. BMJ Case Rep, 2016. doi: 10.1136/bcr-2016-216322

Sugawara, K., Nakayama, N., \& Mochida, S. (2012). Acute liver failure in Japan: definition, classification, and prediction of the outcome. J Gastroenterol, 47(8), 849-861. doi: 10.1007/s00535-012-0624-x

Thayapararajah, S. W., Gulka, I., Al-Amri, A., Das, S., \& Young, G. B. (2013). Acute fulminant hepatic failure, encephalopathy and early CT changes. Can J Neurol Sci, 40(4), 553-557. 